\title{
Agôn
}

Revue des arts de la scène

Critiques | Saison 2011-2012

\section{Adapter n'est pas (forcément) jouer...}

Mefausti, création de Damien Odoul

\section{Caroline Châtelet}

\section{(2) OpenEdition}

1 Journals

Édition électronique

URL : http://journals.openedition.org/agon/1840

DOI : 10.4000/agon.1840

ISSN : 1961-8581

Éditeur

Association Agôn

Référence électronique

Caroline Châtelet, «Adapter n'est pas (forcément) jouer... », Agôn [En ligne], Critiques, mis en ligne le 14 octobre 2011, consulté le 23 septembre 2020. URL : http://journals.openedition.org/agon/1840 ; DOI : https://doi.org/10.4000/agon.1840

Ce document a été généré automatiquement le 23 septembre 2020

Association Agôn et les auteurs des articles 


\title{
Adapter n'est pas (forcément) jouer... \\ Mefausti, création de Damien Odoul
}

\author{
Caroline Châtelet
}

\section{RÉFÉRENCE}

Mefausti, création de Damien Odoul, très librement inspirée de La tragique histoire du Docteur Faust de Christopher Marlowe. Théâtre des Bouffes du Nord, du 4 au 30 octobre 2011

1 C'est fou comme, parfois, les titres en disent beaucoup plus qu'ils ne le soupçonnent sur les spectacles qu'ils nomment... Prenons Mefausti: dans cette libre adaptation de La Tragique histoire du Docteur Faust de Christopher Marlowe, dramaturge élisabéthain prédécesseur de Shakespeare, Damien Odoul propose une contraction entre les noms de Faust et de Méphistophélès. Par ce geste, le metteur en scène souligne la force du rapport noué entre l'homme et le diable à travers le pacte qu'ils signèrent, et qui les lia l'un à l'autre vingt-quatre années durant. Surtout, il suggère qu'en permettant à Faust de voir tous ses désirs accomplis en l'échange de son âme, Méphistophélès projetait sur le jeune homme ses souhaits les plus intimes. C'est donc la vision d'un couple dont l'union tend rapidement vers la fusion et d'un glissement de la focale de Faust vers Méphistophélès que valorise dans le titre et dans les faits Mefausti. Et que Méphistophélès soit incarné par le metteur en scène Damien Odoul et Faust par le comédien Mathieu Amalric - tous deux ayant déjà collaboré précédemment - n'a, ici, rien d'anodin... Ainsi, sur le plateau nu des Bouffes du Nord, c'est OdoulMéphistophélès qui mène la danse : c'est lui qui ouvre et clôture la pièce - entouré de décoratifs et très démonstratifs, car massifs, chiens - ; c'est lui aussi qui, une fois lancé son spectacle, s'assoit dos au public pour observer les échanges à venir, rappelant ici à l'excès son rôle central ; c'est lui qui domine Amalric-Faust; et c'est lui toujours qui introduit d'étranges figures, sorte de Monsieur Loyal de ce ballet de la dépravation. Car 
les êtres gravitant autour de Faust, qu'il s'agisse de sa famille, de figures médiatiques vague renvoi à Bernard Henri-Lévy -, ou de personnages décadents, sont tous traversés par une forme d'étrangeté. Joués par une poignée de comédiens, parmi lesquels on compte un ancien boxeur, un danseur de buto, ou encore une comédienne amateur, ils suscitent lors de leurs apparitions un malaise. Peut-être parce que au-delà de la seule exhibition de leurs particularités physiques ou de jeu, rien ne semble asseoir leur présence. Comme si Damien Odoul avait évacué de sa création toutes direction d'acteurs et intentions véritables... D'où le sentiment d'assister à une composition certes volontairement dissonante, mais hélas désespérément creuse. Au défilé de freaks se livrant à de vagues scènes érotiques mollement provoc' répond la vacuité d'un propos, incapable de dépasser la convocation d'éléments scéniques pour leur seule capacité d'efficacité. À tel point qu'aussi «libre » soit cette adaptation, on s'interroge sur la teneur de l'histoire qui nous est racontée. Car au-delà de la transposition du mythe dans notre société contemporaine, que reste-t-il ? Dans ce bric à brac aux effets dénués de sens, seul demeure, jusqu'à la nausée, le lien de domination existant entre Odoul et Amalric. Mais en se fondant sur rien d'autre que sa propre contemplation, il ne fait que répéter la complaisance d'un metteur en scène pour son personnage, ainsi que son désir de se substituer au comédien qu'il dirige. Voire celui, tout aussi prétentieux, de se regarder évoluer à travers lui...

\section{Mefausti de Damien Odoul}

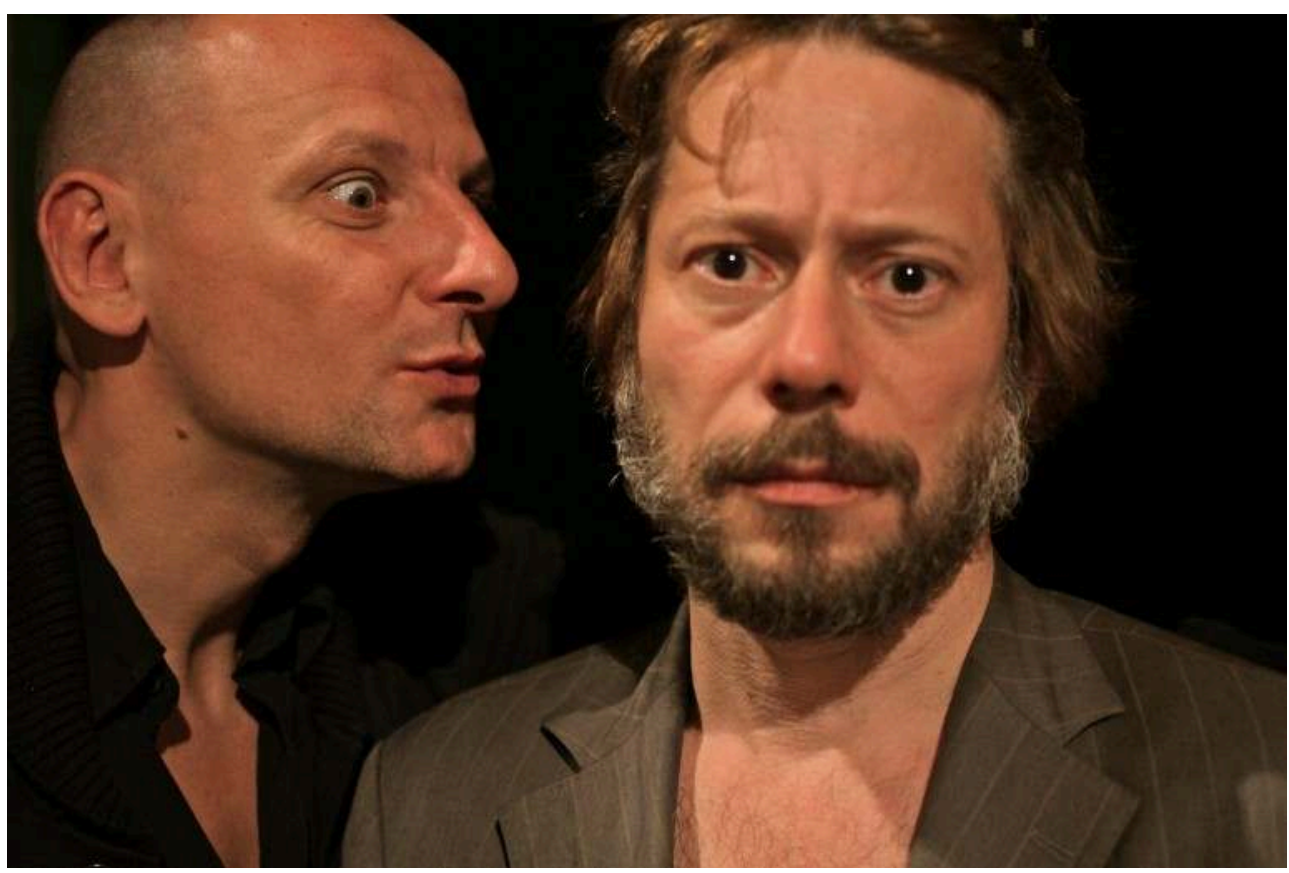

Damien Odoul et Mathieu Amalric

(c) Marie-Eve Nadeau 
INDEX

Mots-clés : Odoul (Damien), Mefausti, Bouffes du Nord 